\title{
Evidence of acute giant cell reaction post bioresorbable vascular scaffold implantation
}

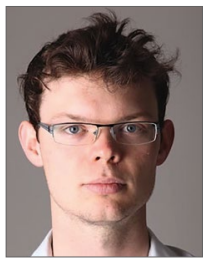

Andrew D. Mulligan ${ }^{1}$, BSc, MBBS; Cheng Yee Goh", MBChB; Sarah Parsons²,3, MBBS;

William Chan ${ }^{1,3,5 *}$, MBBS, PhD

1. Department of Cardiology, Western Health, Melbourne, Australia; 2. Victorian Institute of Forensic Medicine, Melbourne, Australia; 3. Monash University, Melbourne, Australia; 4. Department of Cardiovascular Medicine, Alfred Hospital, Melbourne, Australia; 5. Melbourne Medical School, Faculty of Medicine, Dentistry, and Health Sciences, The University of Melbourne, Melbourne, Australia
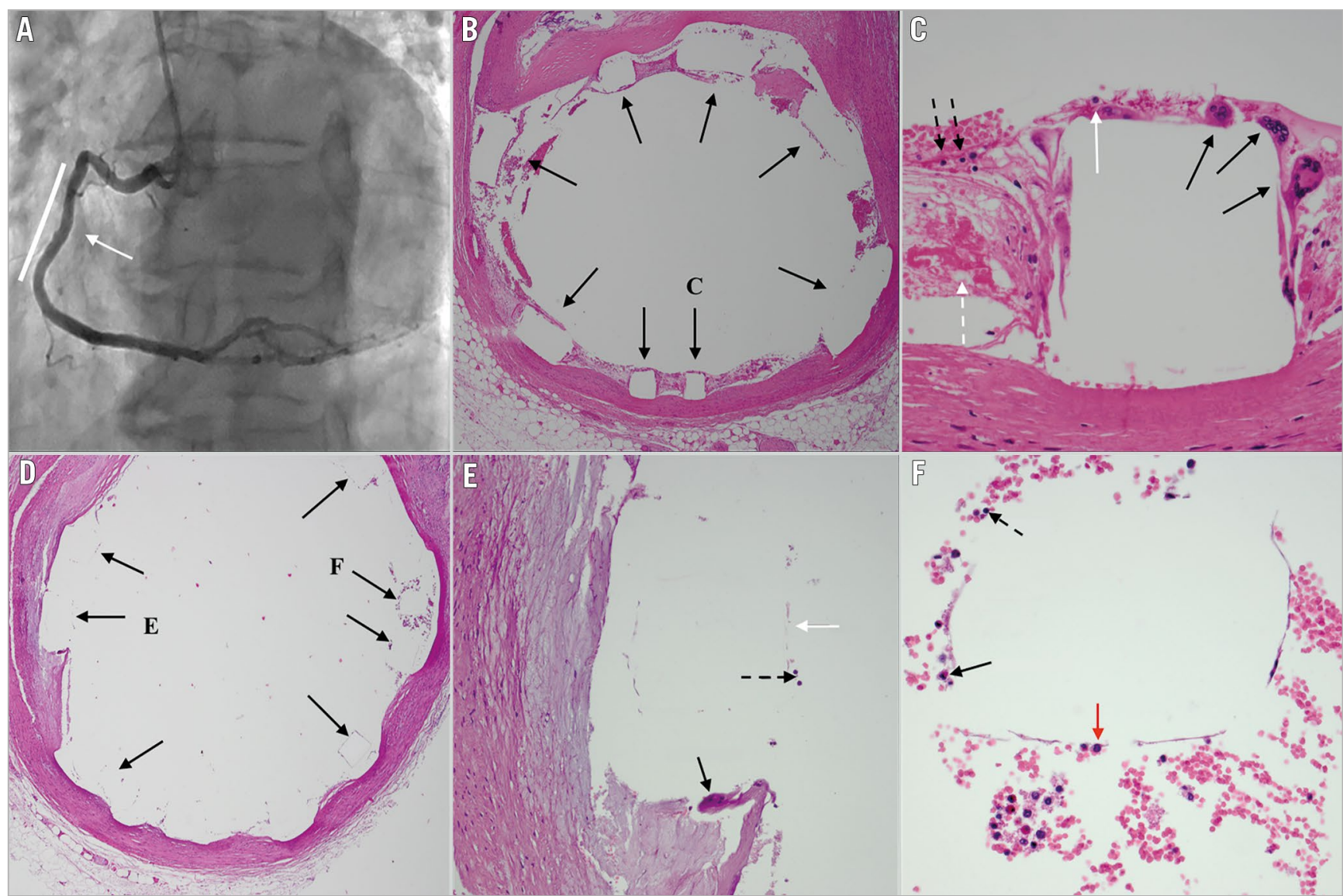

*Corresponding author: Cardiology Department, Western Health, Gordon St, Footscray, Victoria 3011, Australia. E-mail:William.chan@unimelb.edu.au 
A 53-year-old man died in the coronary care unit of refractory ventricular fibrillation arrest, despite advanced life support resuscitative efforts, 150 minutes post implantation of an Absorb ${ }^{\mathrm{TM}}$ (Abbott Vascular, Santa Clara, CA, USA) bioresorbable vascular scaffold (BVS) in the mid right coronary artery (RCA) (Panel A, white line) due to right ventricular marginal branch occlusion by the BVS (Panel A, white arrow). The mid RCA stenosis was predilated with a $2.5 \times 15 \mathrm{~mm}$ compliant balloon, followed by implantation of $3.5 \times 28 \mathrm{~mm}$ Absorb BVS deployed at $16 \mathrm{~atm}$ and post-dilated with a $3.75 \times 8 \mathrm{~mm}$ non-compliant balloon at $18 \mathrm{~atm}$. This was 30 days after percutaneous coronary intervention (PCI) to the mid left anterior descending artery (LAD) with two overlapping Absorb BVS.

Post-mortem histopathology of the RCA BVS demonstrated square punched out areas representing the scaffold struts (Panel B, black arrows). Examination of a single representative strut demonstrated seven giant cells (Panel C, black arrows), five macrophages (Panel C, white arrow), and four polymorphonuclear leukocytes (PMN) (Panel C, black dashed arrows) and fibrin (Panel C, white dashed arrow), along the edge of the strut.

The LAD BVS that was inserted 30 days prior was also examined to compare with the findings of the RCA. The outline of the struts can be seen (Panel D, black arrows; Panel E, white arrow). A representative section of the LAD BVS revealed occasional giant cells (Panel E, black arrow), PMN (Panel E, black dashed arrow; Panel F, black dashed arrow), eosinophil (Panel F, black arrow) and macrophage (Panel F, red arrow). The intima and media also showed giant cells, macrophages and PMN associated with cholesterol clefts.

Foreign body type giant cells are formed when a foreign particle size exceeds the capacity of a macrophage to engulf it $^{1}$. They are commonly observed around biomaterial implants that stimulate an immune or inflammatory response, and are thought to be responsible for the degradation of biodegradable products ${ }^{1}$.

Giant cell reaction has previously been observed as early as day 3 with $\mathrm{BVS}^{2}$. A study using optical coherence tomography demonstrated that one third of BVS are fully resorbed at two years, and all BVS at five years ${ }^{3}$. The heterogeneity in the resorption rate can be explained by the relationship between the rate of material degradation and the degree of inflammatory response to the material $^{1}$. Abnormal immune responses to stents have been previously described such as eosinophilic hypersensitivity reactions in firstgeneration sirolimus drug-eluting stents ${ }^{2}$.

Although long-term data exist for the Absorb BVS, the acute or short-term inflammatory response remains poorly understood. This is the earliest report of foreign body type giant cell reaction to Absorb BVS in humans.

\section{Conflict of interest statement}

The authors have no conflicts of interest to declare.

\section{References}

1. Jiang WW, Su SH, Eberhart RC, Tang L. Phagocyte responses to degradable polymers. J Biomed Mater Res A. 2007;82:492-7.

2. Kraak RP, de Boer HH, Elias J, Ambarus CA, van der Wal AC, de Winter RJ, Wykrzykowska JJ. Coronary Artery Vessel Healing Pattern, Short and Long Term, After Implantation of the EverolimusEluting Bioresorbable Vascular Scaffold. J Am Heart Assoc. 2015;4(11).

3. Simsek C, Karanasos A, Magro M, Garcia-Garcia HM, Onuma Y, Regar E, Boersma E, Serruys PW, van Geuns RJ. Longterm invasive follow-up of the everolimus-eluting bioresorbable vascular scaffold: five-year results of multiple invasive imaging modalities. EuroIntervention. 2016;11:996-1003. 